\title{
STUDY THE EFFECT OF SOME OPERATIONAL FACTORS ON HAMMER MILL
}

\section{El Shal ,M.S. ${ }^{1}$; M.A. Tawfik $^{2}$; A.M. El Shal ${ }^{2}$ and K. A. Metwally ${ }^{3}$}

ABSTRACT

The experiments of this study were carried out during the agricultural seasons of 2007/2008 and 2008/2009 at a private mill for milling grains in Abou Kbeer district, Sharkia Governorate to optimize some operating parameters affecting the performance of a prototype hammer mill. The performance of hammer mill was evaluated under different parameters including drum rotational speed, grain moisture content, hammer thickness and concave clearance. The performance of hammer mill was evaluated taking into consideration hammer mill capacity, efficiency, particle size distribution (fineness degree), power, energy requirement and operational cost. The obtained results reveal that it is recommended to use the hammer mill at drum rotational speed about $2250 \mathrm{rpm}$ $(33.56 \mathrm{~m} / \mathrm{s})$,grain moisture content of $10 \%$, concave clearance of $5 \mathrm{~mm}$ and hammer thickness of $5 \mathrm{~mm}$ to produce pelleting feed by increasing the percentage of fine milled corn (FMC) and decreasing coarse milled corn $(C M C)$. Producing mash feed for commercial use can be achieved by using the mill at drum rotational speed about $1550 \mathrm{rpm}(23.85 \mathrm{~m} / \mathrm{s})$, grain moisture content of 14\%,concave clearance of $12 \mathrm{~mm}$ and hammer thickness of $1.5 \mathrm{~mm}$ by decreasing percentage of fine milled corn (FMC) and increasing coarse milled corn (CMC) and medium milled corn $(M M C)$.

\section{INTRODUCTION}

$\mathrm{N}$ owadays, the development of animal and poultry production needs to exert more efforts to increase and maintain high levels of feeding crop, in addition to improve the quality and quantity by decreasing grain losses during pre- processing operation, selecting the proper diet in the acceptable phase of livestock and reducing the consumed energy. The hammer mill is used almost exclusively in preparation of broiler rations because of its simplicity, ease to operate and

${ }^{1}$ Prof. Emeritus, Agric. Eng. Dept., Fac. of Agric., Zagazig Univ., Egypt ${ }^{2}$ Lecturer, Agric. Eng. Dept., Fac. of Agric., Zagazig Univ., Egypt.

${ }^{3}$ Demonstrator, Agric. Eng. Dept., Fac. of Agric., Zagazig Univ., Egypt. 
low maintenance cost so, it had been widely spread in most of the poultry farms in Egypt, for this reason, such care had to be taken to evaluate this type of mills for better utilization by several investigations to improve its performance. Martin (1983) stated that using large particle size for the grain component of the diet is attractive because of the substantial reduction of energy for grinding that would if the grain could be less finely ground without adverse effects. He added that ingredients with widely varying particle sizes are more difficult to mix properly, and large particles tend to segregate from smaller ones during subsequent handling after mixing. Ensminger et al. (1990) showed that very fine grinding makes feeds dusty and lower palatability. However, fine grinding may be desirable when pelleting is to follow. Hassan (1994) found that increasing of drum speed from 1460 to 2930 and $3910 \mathrm{rpm}$ gave a decrease of 59.1 and $67.9 \%$ in grinding energy. The increase of the grain moisture content from 5.4 to 8.1 and $11.4 \%$ gave an increase of 20.1 and $49 \%$ in grinding energy. He added that the fine grinding percentage was obtained at lower grain moisture content and higher drum speed. In addition, as to fineness degree of grinding (medium and coarse) an opposite trend results comparing with the fine grinding. EL- Gayar and Bahnas (2002) studied some factors affecting on hammer mill to produce garlic power such as three hammer tip speeds (13.82, 18.43 and $23.04 \mathrm{~m} / \mathrm{s}$ ), two feed rates $(27.00$ and $43.2 \mathrm{~kg} / \mathrm{h}$ ) two screen hole diameters (1 and $2 \mathrm{~mm}$ ) and two drying methods ( natural and artificial) .They indicated that the highest milling capacity was obtained at $23.04 \mathrm{~m} / \mathrm{s}$ hammer tip speed and the highest milling efficiency was obtained at $13.82 \mathrm{~m} / \mathrm{s}$ hammer tip speed and the milling efficiency takes the opposite trend of the milling capacity. Hegazy et al. (2002) indicated that increasing hammer revolving speeds from 1000 to $2500 \mathrm{rpm}$ (16.6 to 41.5 $\mathrm{m} / \mathrm{s}$ ) cause a corresponding increase in the machine productivity. Hence, the objectives of the present study are to (1) evaluate hammer mill prototype during grinding corn grains.(2) study some operating and engineering parameters (grain moisture content, drum rotational speed, hammer thickness and concave clearance) which affecting the performance of the hammer mill (3) Estimate the hammer mill operational cost. 


\section{MATERIALS AND METHODS}

The experiments of this study were conducted during agricultural seasons of 2007/2008 and 2008/2009 at a private mill for milling grains in Abou Kbeer district, Sharkia Governorate to optimize some operating parameters affecting the performance of swinging hammer mill prototype.

\section{A-Materials:}

\section{-Corn Grain:}

Experiments were carried out on yellow corn grain (variety of Giza 162) at different moisture contents. Some physical properties of the used corn grains are given in Table (1).

Table (1): Some physical properties of corn grain.

\begin{tabular}{|c|c|c|c|c|}
\hline variety & $\begin{array}{c}\text { Bulk density } \\
, \mathrm{gm} / \mathrm{cm}^{3}\end{array}$ & $\begin{array}{c}\text { Average } \\
\text { length }, \mathrm{mm}\end{array}$ & $\begin{array}{c}\text { Average width } \\
, \mathrm{mm}\end{array}$ & $\begin{array}{c}\text { Average thickness } \\
\text {,mm }\end{array}$ \\
\hline Giza 162 & 0.680 & 10.75 & 8.65 & 4.9 \\
\hline
\end{tabular}

\section{-Screens (3mm and $4.2 \mathrm{~mm}$ diameter):}

Two different diameters of screen holes were used to determine the particle size distribution (fineness degree).Other instruments and devices were used in the experiments such as stop watch, grain moisturmeter, electronic balance, varnier caliper, tachometer and clamp meter.

\section{-Hammer mill prototype:}

The mill specifications are shown in Fig.(1) and Table(2).

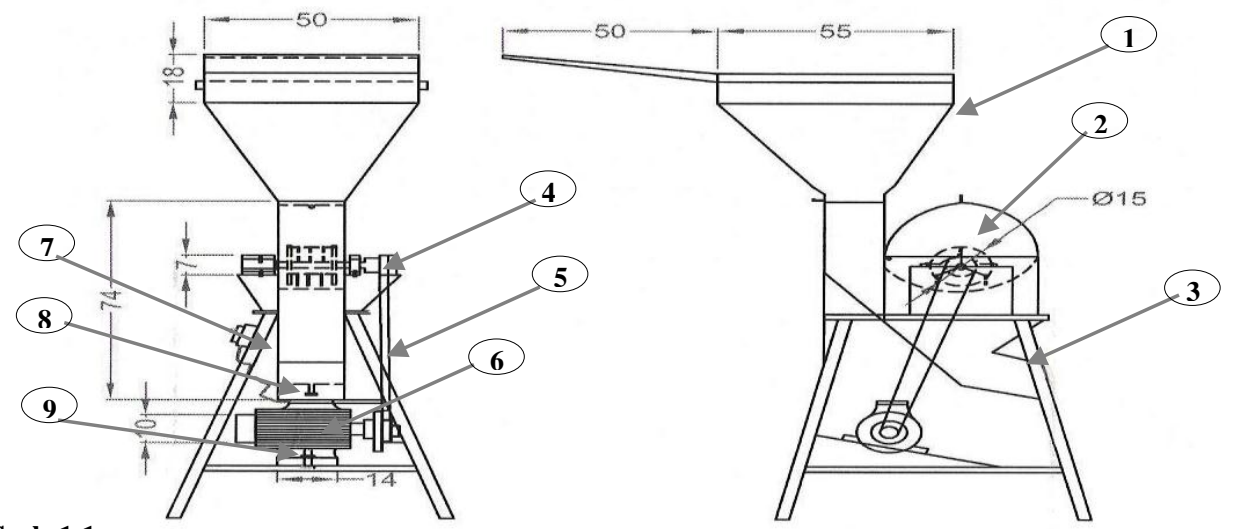

Scale 1:1

Dimensions in cm Side view

\section{Elevation}

Fig. (1): Elevation and side view of hammer mill prototype

(1) Feed hopper, (2) Crushing chamber, (3) Outlet, (4) Pulleys, (5) Belt, (6) Motor, (7) Operating button, (8) Clearance adjustment screw, (9) Belt adjustment screw 
Table (2): The specifications of the hammer mill prototype, hammers and screen.

\begin{tabular}{|c|c|}
\hline 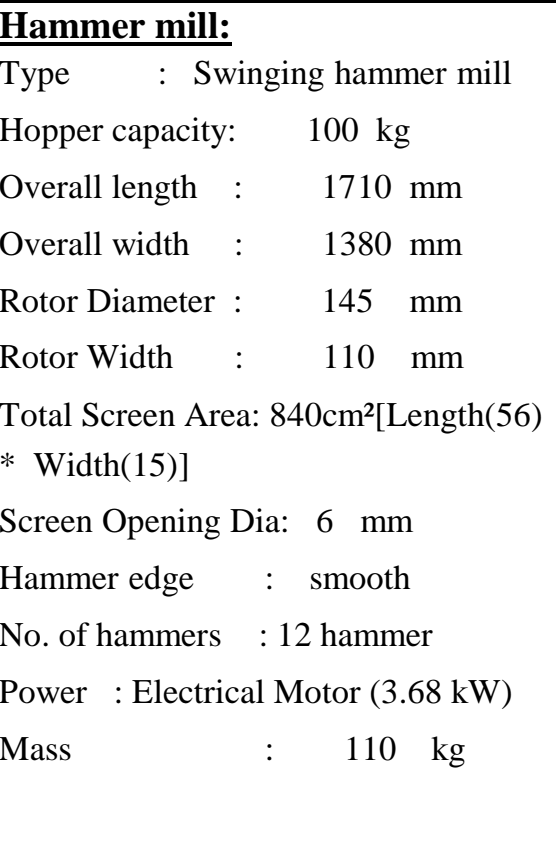 & 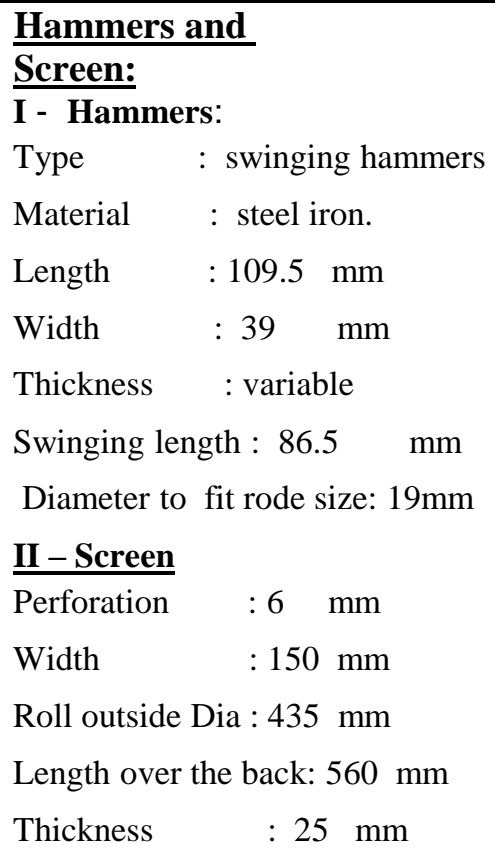 \\
\hline
\end{tabular}

\section{B-Methods:}

The milling experiments were carried out to optimize some operating parameters affecting the performance of hammer mill prototype these parameters are:

1-Four drum rotational speeds of 1550, 1800, 2000 and 2250 r.p.m corresponding to drum peripheral speeds of $(23.12,26.85,29.83$ and $33.56 \mathrm{~m} / \mathrm{s}$ ) respectively.

2-Three levels of grain moisture content of 10,12 and14\% (w.b).

3-Three hammer thickness of $1.5,3$ and $5 \mathrm{~mm}$.

4-Three concave clearances of 5,8 and $12 \mathrm{~mm}$.

\section{C-MEASUREMENTS:}

Evaluation of the hammer mill was performed taking into consideration the following indicators:

\section{Milling capacity and efficiency:}

The theoretical milling capacity (TMC) of the machine is the rate of productivity if the machine performed $100 \%$ of the instant time. The 
actual milling capacity (AMC) of the machine is the actual rate of productivity by the amount of actual time consumed in operation (lost + productive time).Lost time is considered as the time spend in refilling the machine hopper, interruptions and simple repairs. The milling efficiency $\left(\eta_{m}\right)$ was calculated using the following equation:

$$
\begin{aligned}
& \eta_{m}=\frac{A \cdot M \cdot C}{T \cdot M \cdot C} * 100 \\
& \eta_{m}=\text { The milling efficiency, } \% . \\
& \text { T.M.C }=\text { The theoretical machine capacity, } \mathrm{Mg} / \mathrm{h} \text {. }
\end{aligned}
$$

A.M.C = The actual machine capacity, $\mathrm{Mg} / \mathrm{h}$.

\section{Fineness Degree (particle size distribution):}

The ground corn samples were classified into three main categories according to Henderson and Hansen(1968). The first one is fine milled corn FMC $(<3 \mathrm{~mm})$, the second is medium milled corn MMC $(3-4.2 \mathrm{~mm})$ and the third is coarse milled corn CMC (>4.2 mm).

\section{Milling power and energy requirement:}

The require milling power was estimated by using the following equation (Ibrahime, 1982):

Total consumed power $=$ load

$$
=\frac{\sqrt{3} I \cdot V \eta \cos \theta}{1000}
$$

Where:

$\mathrm{I}=$ line current strength in Amperes.

$\mathrm{V}=$ Potential strength (voltage) being equal to $390 \mathrm{~V}$. $\cos \theta=$ power factor (being equal to 0.84 ).

$\eta=$ Mechanical efficiency assumed (95\%).

The specific energy requirement $(\mathrm{kW} . \mathrm{h} / \mathrm{Mg})$ was calculated by using the following equation:

The specific energy requirement $(\mathrm{kW} . \mathrm{h} / \mathrm{Mg})=\frac{\text { The consumed power }(\mathrm{kW})}{\text { Actual milling capacity }(\mathrm{Mg} / \mathrm{h})}$ 


\section{Operating cost:}

Operatingcost $(\mathrm{L} . \mathrm{E} / \mathrm{Mg})=\frac{\text { Machinecost }(\mathrm{L} . \mathrm{E} / \mathrm{h})}{\text { Actualmillingcapacity }(\mathrm{Mg} / \mathrm{h})}$

The machine cost was determined by using the following formula (Awady et al.,2003) :

$$
C=\frac{p}{h}\left(\frac{1}{a}+\frac{i}{2}+t+r\right)+(W . e)+\frac{m}{144}
$$

Where:

C : Machine hourly cost, L.E./h.

$P$ : Price of machine, L.E.

$\mathrm{h}$ : Yearly working hours.

a : Life expectancy of the machine, year.

i : Interest rate/year .

$\mathrm{t}$ : Taxes and over heads ratio, $\%$.

r: Repairs and maintenance ratio, $\%$.

$\mathrm{W}$ : Power of motor, $\mathrm{kW}$.

e : Hourly cost/kW.h.

$\mathrm{m}$ : The monthly average wage, L.E.

144: The monthly average working hours.

\section{RESULTS AND DISCUSSION}

\section{- Milling Capacity and Efficiency:}

Figs. (2) to (4) showed the relation between drum speed and both of machine capacity and efficiency under different grain moisture content, hammer thickness and concave clearance. It was noticed that the increase of drum speed was accompanied with an increase in machine capacity and a decrease in machine efficiency that can be attributed to the loss in refilling time for refilling the hammer mill hopper increases consequently, the milling efficiency decrease hence, the milling efficiency taken the opposite trend of the milling capacity with drum speed. The highest value of machine capacity of $(0.871 \mathrm{Mg} / \mathrm{h})$ obtained at drum speed of $2250 \mathrm{rpm}(33.56 \mathrm{~m} / \mathrm{s})$, grain moisture content of $10 \%$, concave clearance of $5 \mathrm{~mm}$ and hammer thickness of $5 \mathrm{~mm}$. while, the highest value of machine efficiency $(92.9 \%)$ obtained at drum speed of $1550 \mathrm{rpm}(23.12 \mathrm{~m} / \mathrm{s})$, grain moisture content of $14 \%$, concave clearance of $12 \mathrm{~mm}$ and hammer thickness of $1.5 \mathrm{~mm}$. 

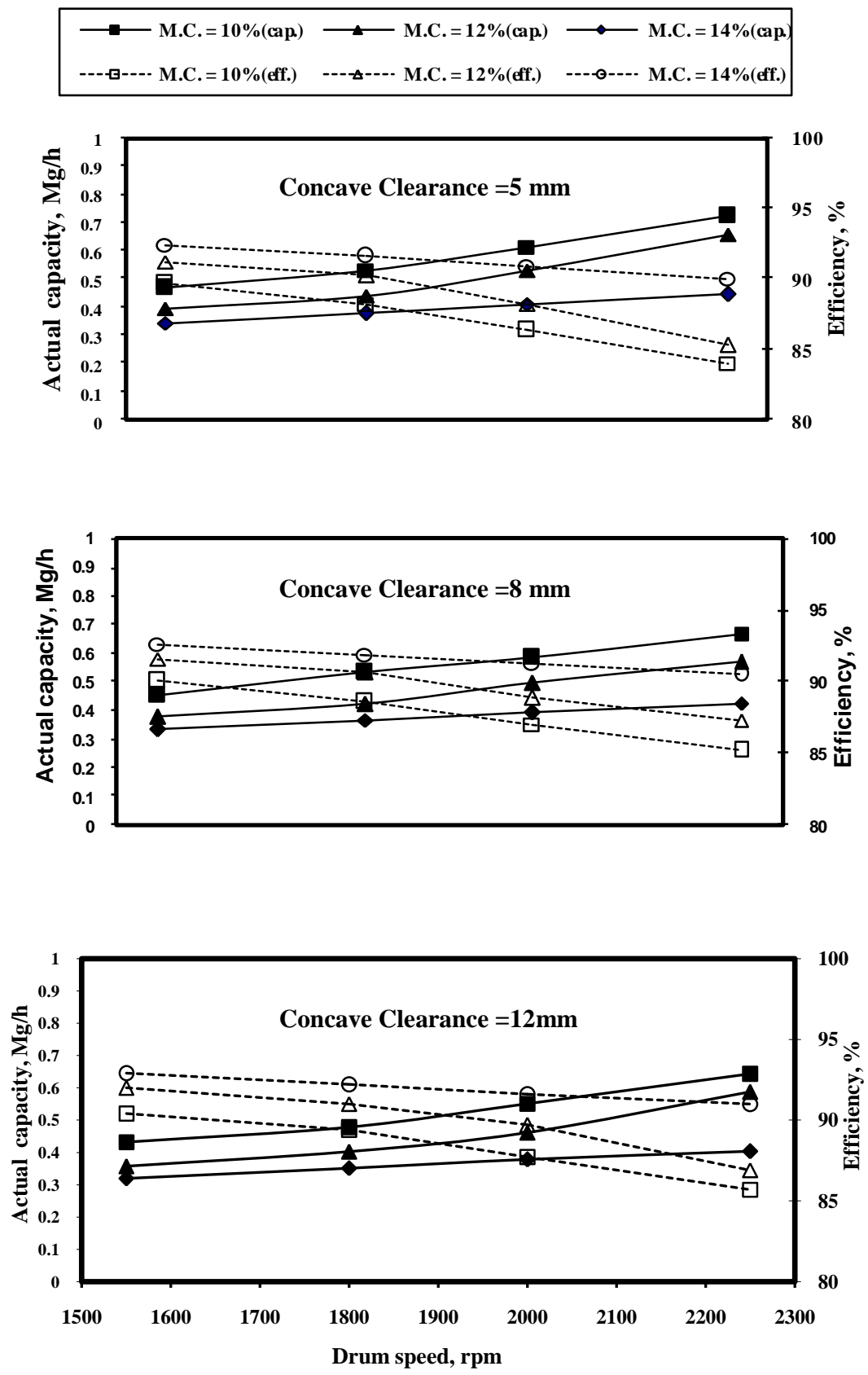

Fig. (2): Effect of drum speed on machine capacity and efficiency under different moisture contents and concave clearances at hammer thickness of $1.5 \mathrm{~mm}$ 

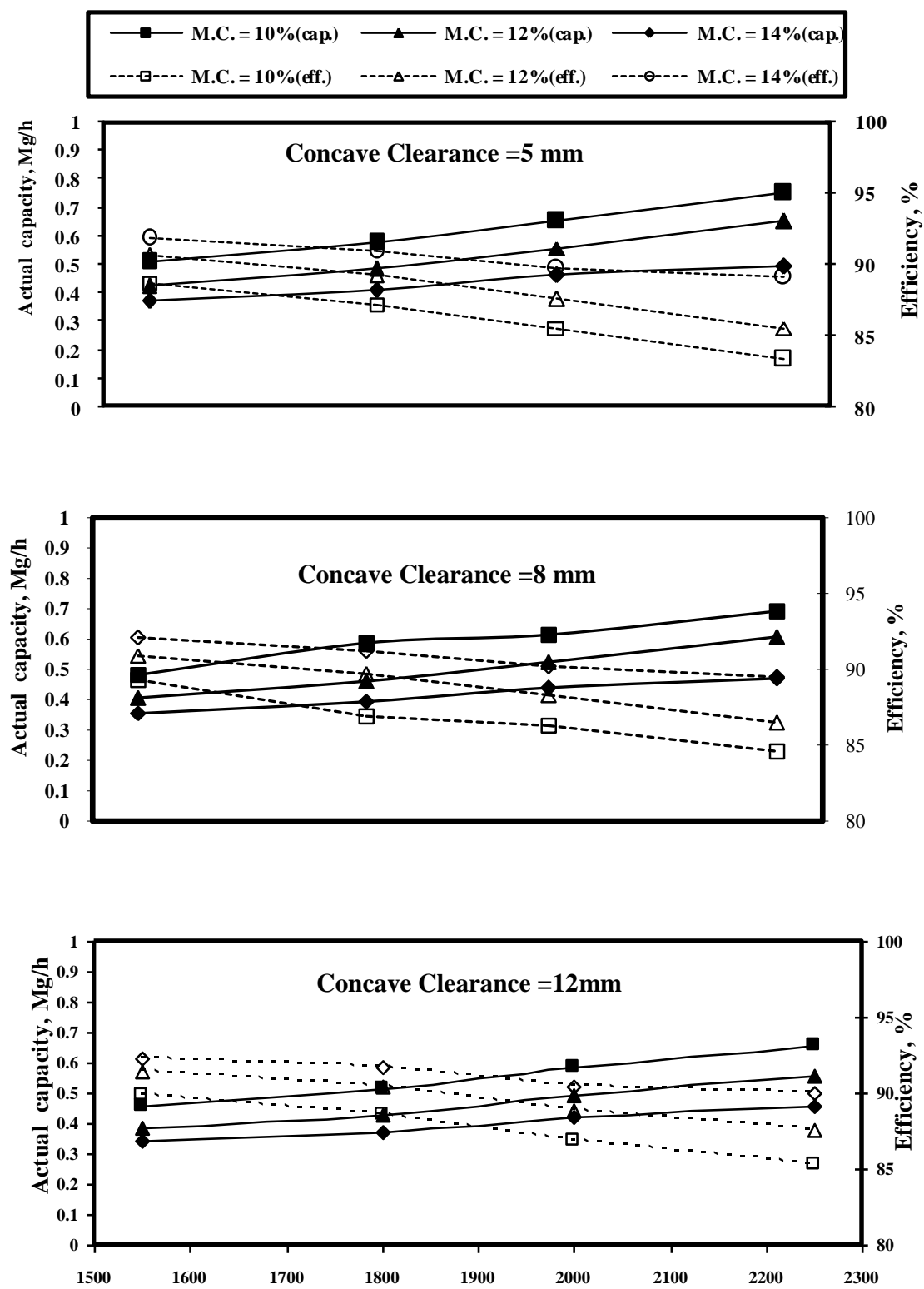

Drum speed, rpm

Fig.(3):Effect of drum speed on machine capacity and efficiency under different moisture contents and concave clearances at hammer thickness of $\mathbf{3 m m}$. 

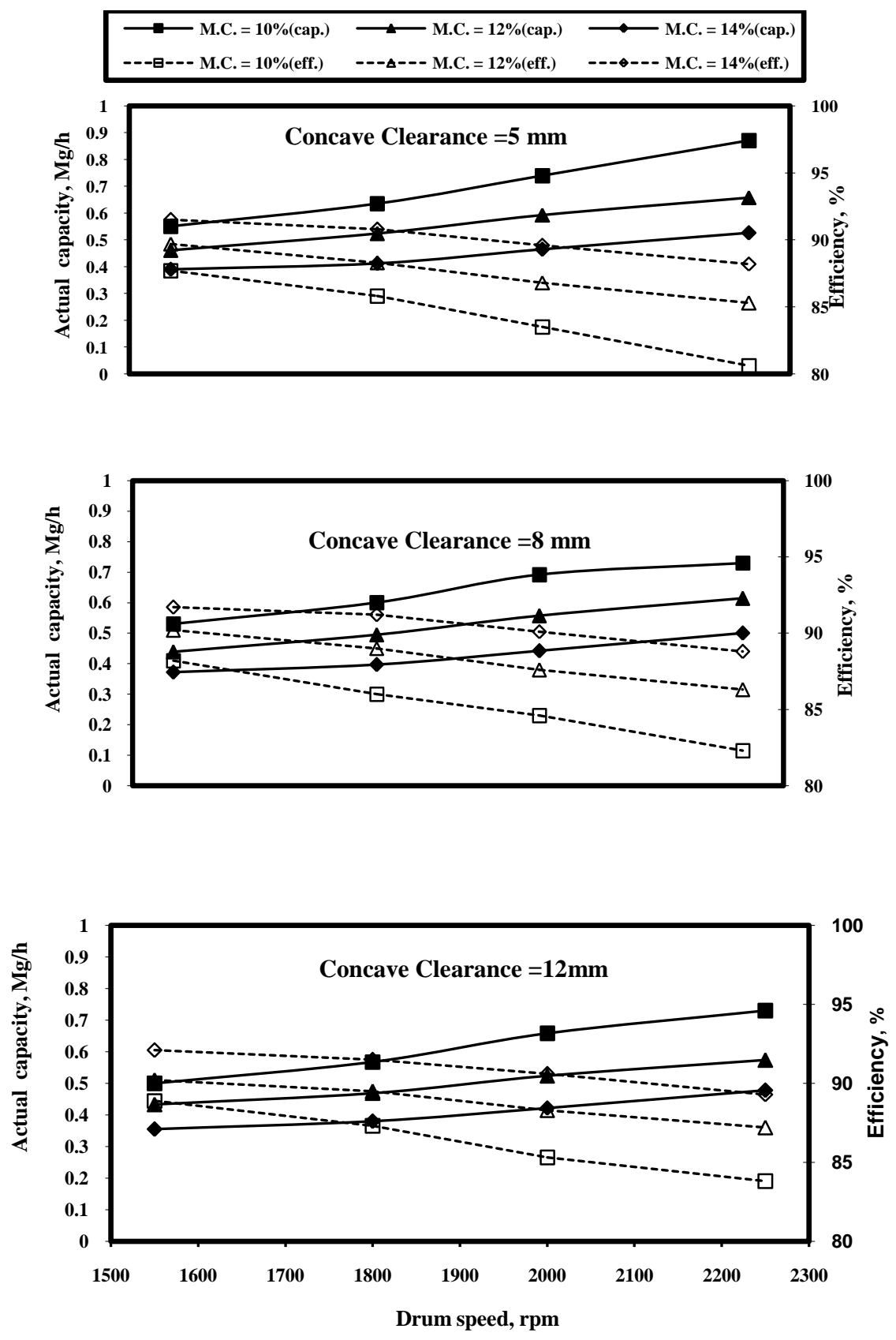

Fig.(4):Effect of drum speed on machine capacity and efficiency under different moisture contents and concave clearances at hammer thickness of $\mathbf{5 m m}$ 

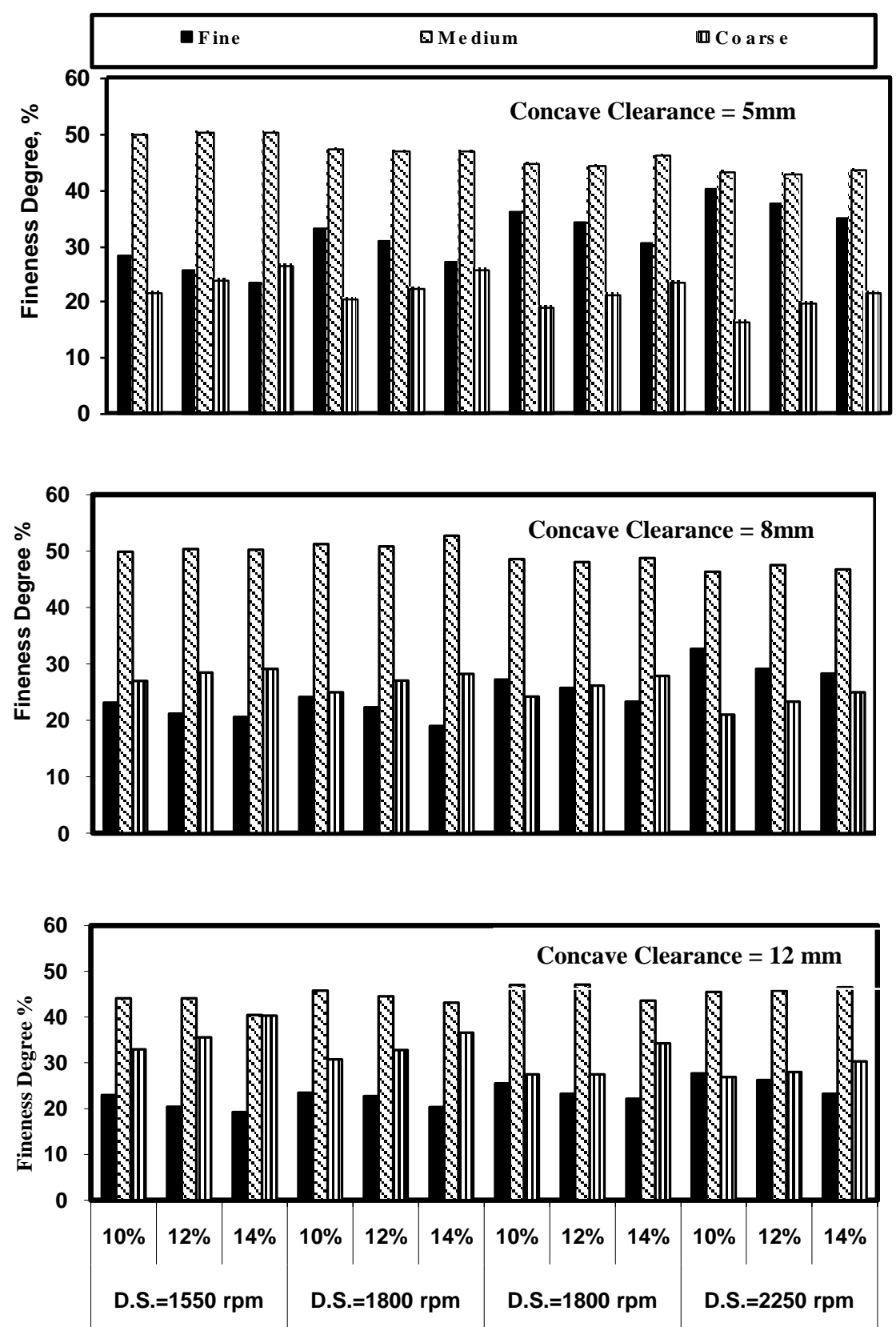

Fig.(5):Effect of drum speed on fineness degree under different moisture contents and concave clearances at hammer thickness of $1.5 \mathrm{~mm}$. 

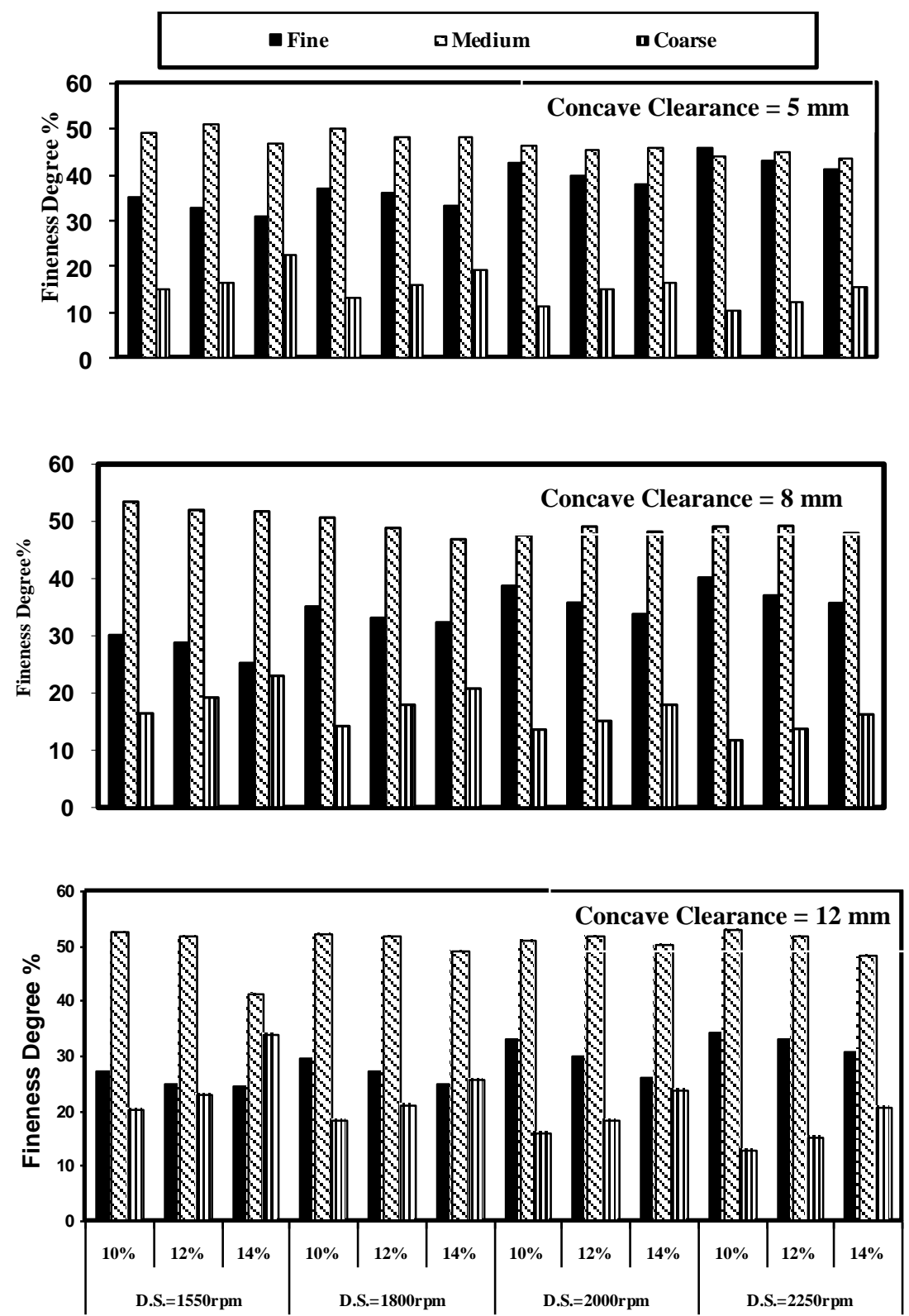

Fig.(6):Effect of drum speed on fineness degree under different moisture contents and concave clearances at hammer thickness of $3 \mathrm{~mm}$. 

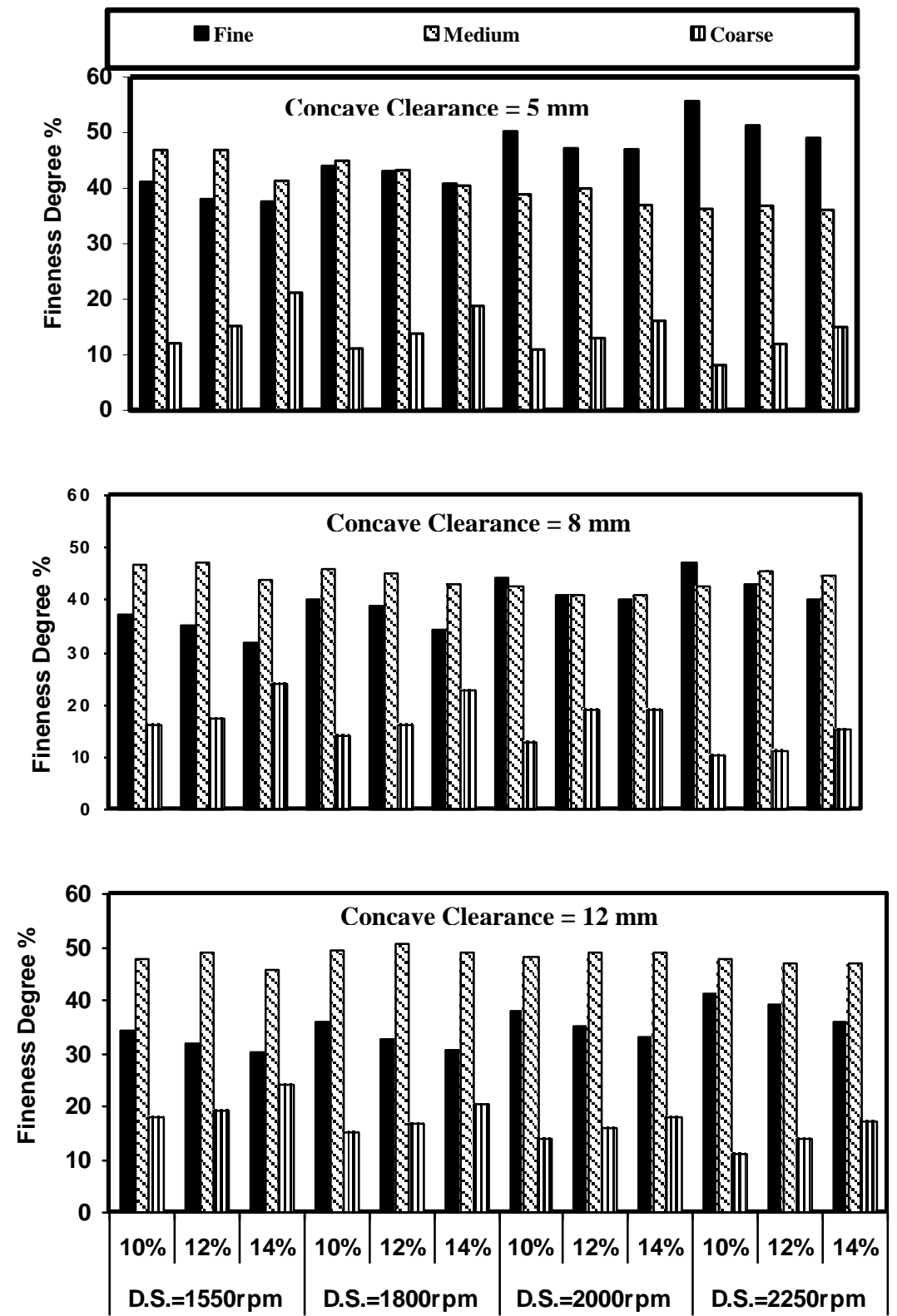

Fig.(7):Effect of drum speed on fineness degree under different moisture contents and concave clearances at hammer thickness of $5 \mathrm{~mm}$. 


\section{Fineness Degree:}

In Figs. (5) to (7) which showed the relation between drum speed and fineness degree under different grain moisture contents, hammer thickness and concave clearances. It was cleared that the increase of drum speed was followed with an increase in fine milled corn (FMC\%) while coarse milled corn (CMC\%) decrease. The highest value of (FMC\%) of $(55.33 \%)$ obtained at drum speed of 2250 r.p.m $(33.56 \mathrm{~m} / \mathrm{s})$, grain moisture content of $10 \%$, hammer thickness of $5 \mathrm{~mm}$ and concave clearance of $5 \mathrm{~mm}$ while, the highest value of (CMC\%) of $(40.33 \%)$ obtained at drum speed of 1550 r.p.m $(23.12 \mathrm{~m} / \mathrm{s})$, grain moisture content of $14 \%$, hammer thickness of $1.5 \mathrm{~mm}$ and concave clearance of $12 \mathrm{~mm}$. Finally, the highest value of medium milled corn (MMC\%) of $(53.41 \%)$ obtained at drum speed of 1550 r.p.m $(23.12 \mathrm{~m} / \mathrm{s})$. grain moisture content of $10 \%$ hammer thickness of $3 \mathrm{~mm}$ and concave clearance of $8 \mathrm{~mm}$.

\section{-Energy requirement:}

The relation between drum speed and specific energy requirement under different grain moisture contents, hammer thickness and concave clearances was represented in Figs.(8) to (10). It was observed that the increase of drum speed was occurred a decrease in specific energy requirement that is can be attributed to increasing of machine capacity rate is higher than increasing in power required rate. The lowest value of specific energy requirement $(3.53 \mathrm{~kW} . \mathrm{h} / \mathrm{Mg})$ obtained at drum rotational speed of $2250 \mathrm{rpm}(33.56 \mathrm{~m} / \mathrm{s})$, grain moisture content of $10 \%$, concave clearance of $5 \mathrm{~mm}$ and hammer thickness of $5 \mathrm{~mm}$.

\section{-Operational cost:}

Figs.(11) to (13) showed the relation between drum rotational speed and operational cost under different grain moisture contents, hammer thickness and concave clearances. It was noticed that the increase of drum rotational speed was occurred a decrease in operational cost that is can be attributed to increasing in machine capacity. The lowest value of operational cost (14.06 L.E./Mg) obtained at drum rotational speed of $2250 \mathrm{rpm}(33.56 \mathrm{~m} / \mathrm{s})$, grain moisture content of $10 \%$, concave clearance of $5 \mathrm{~mm}$ and hammer thickness of $5 \mathrm{~mm}$. 

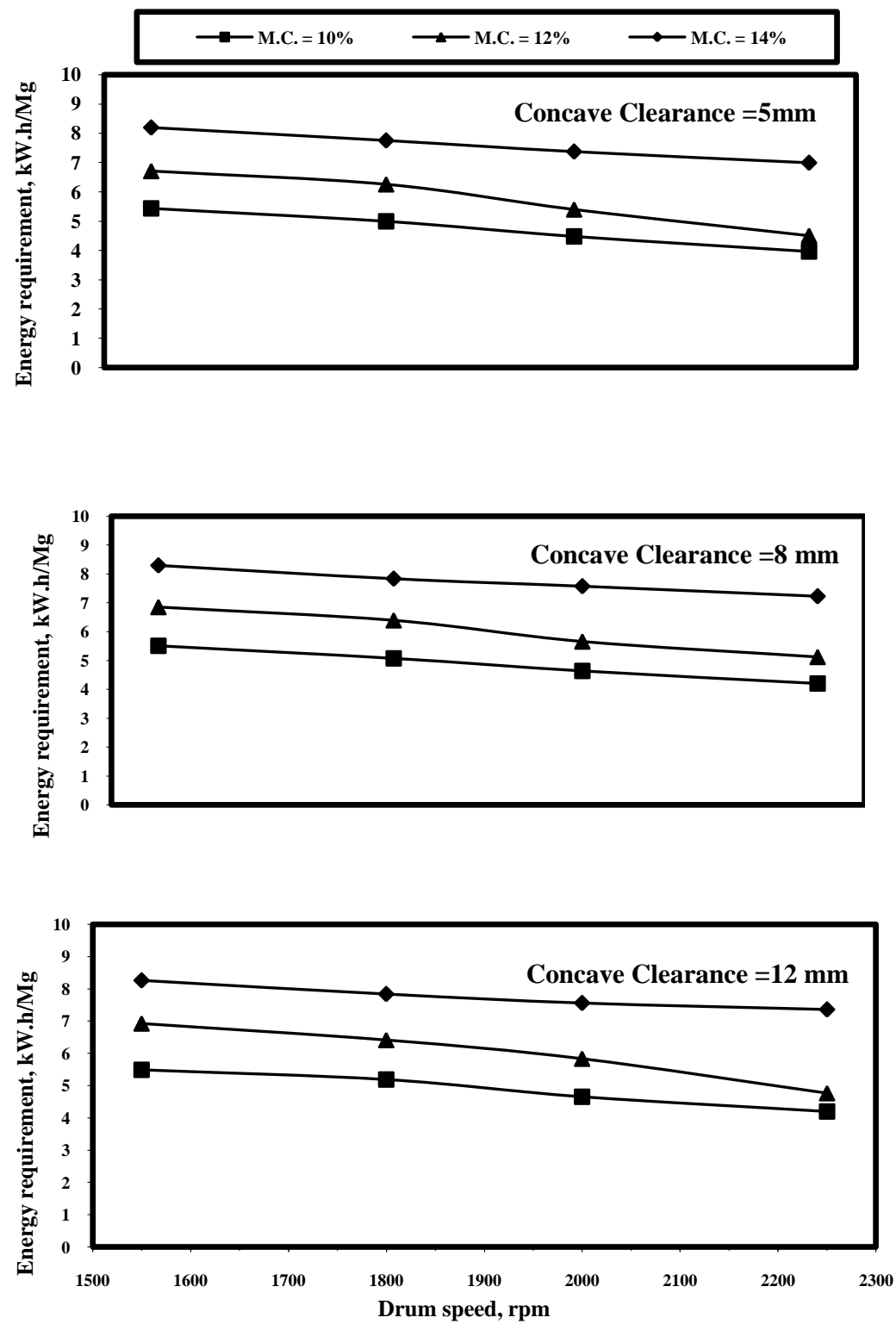

Fig.(8):Effect of drum speed on specific energy requirement under different moisture contents and concave clearances at hammer thickness of $1.5 \mathrm{~mm}$. 

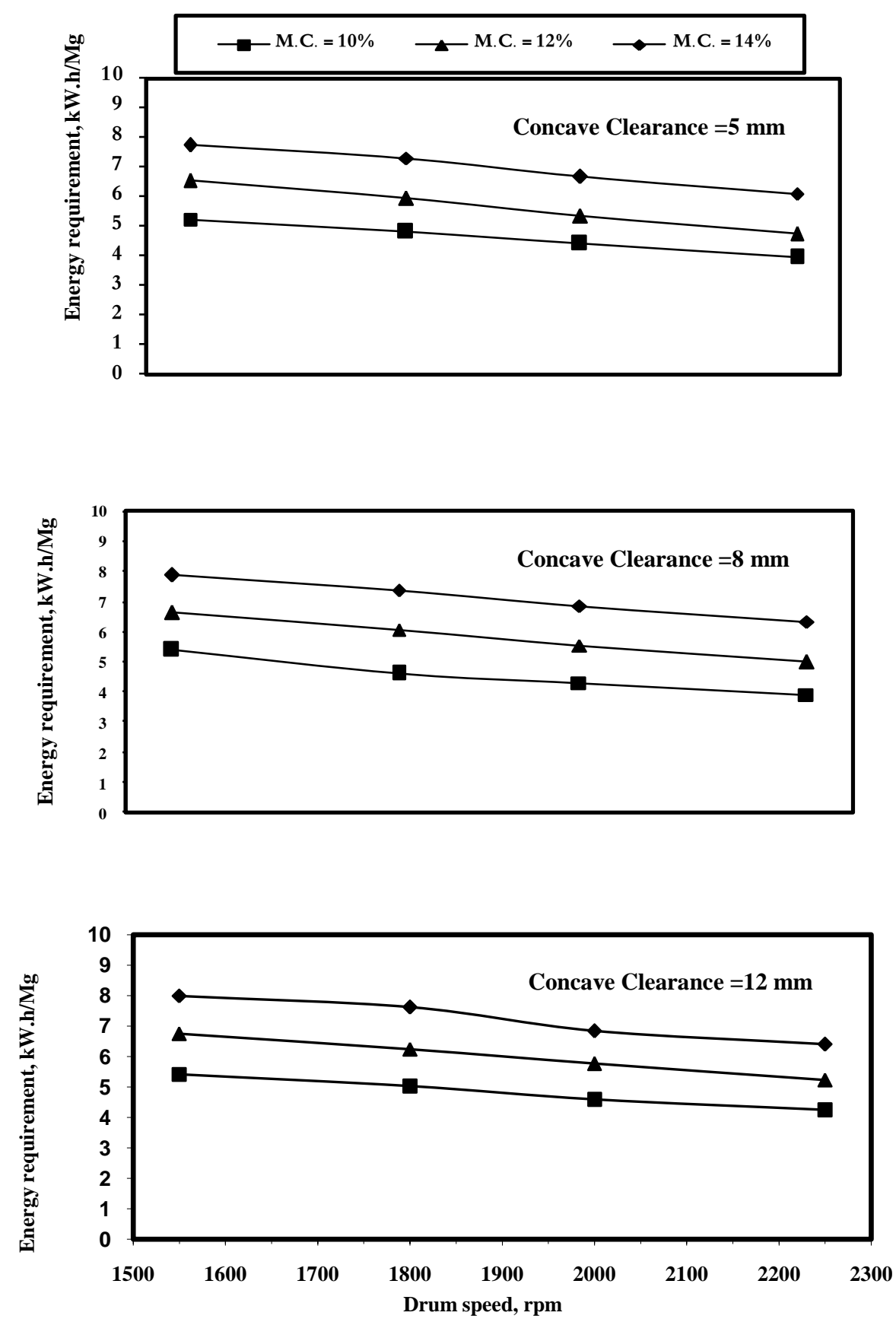

Fig.(9):Effect of drum speed on specific energy requirement under different moisture contents and concave clearances at hammer thickness of $3 \mathrm{~mm}$. 

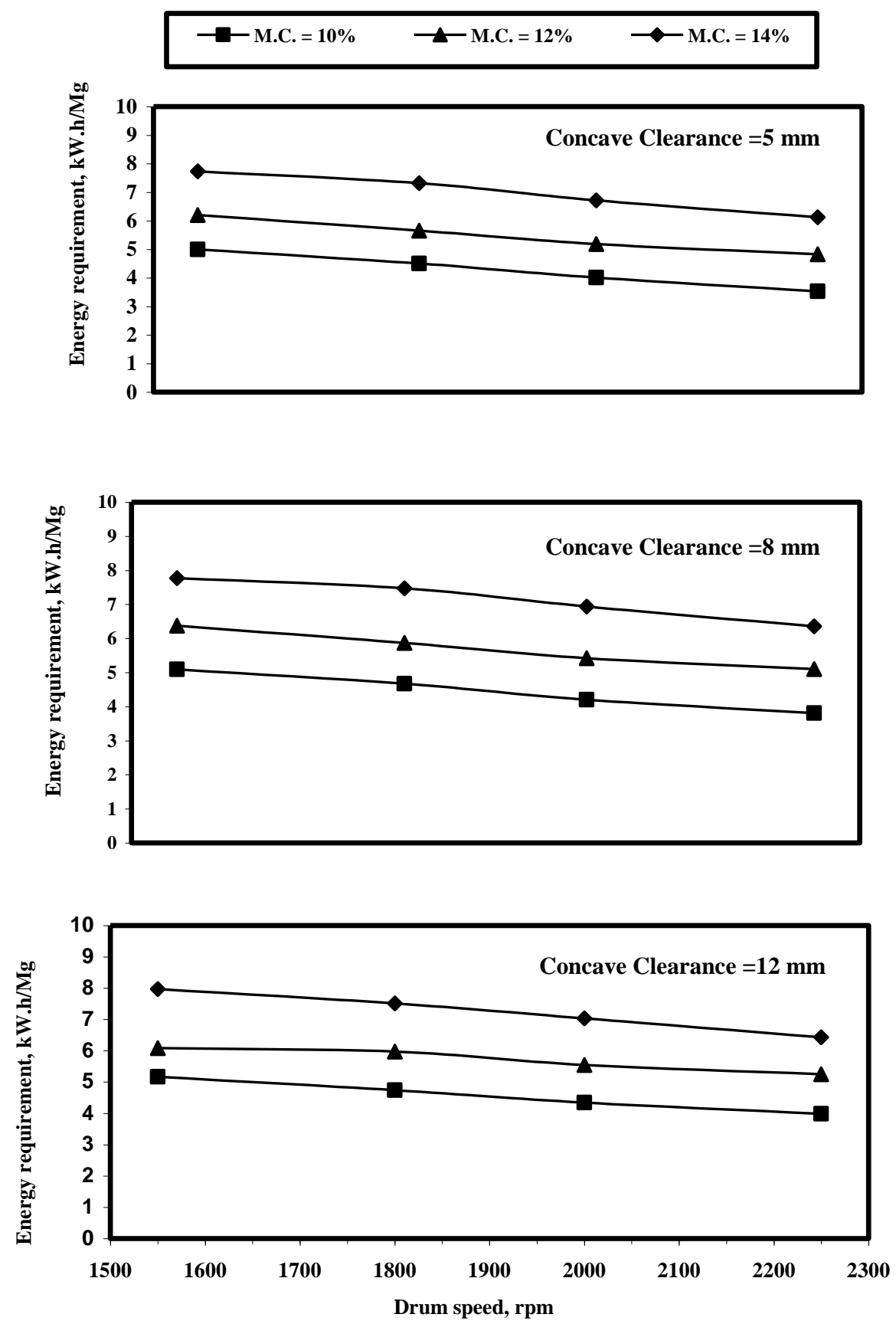

Fig.(10):Effect of drum speed on specific energy requirement under different moisture contents and concave clearances at hammer thickness of $\mathbf{5 m m}$. 

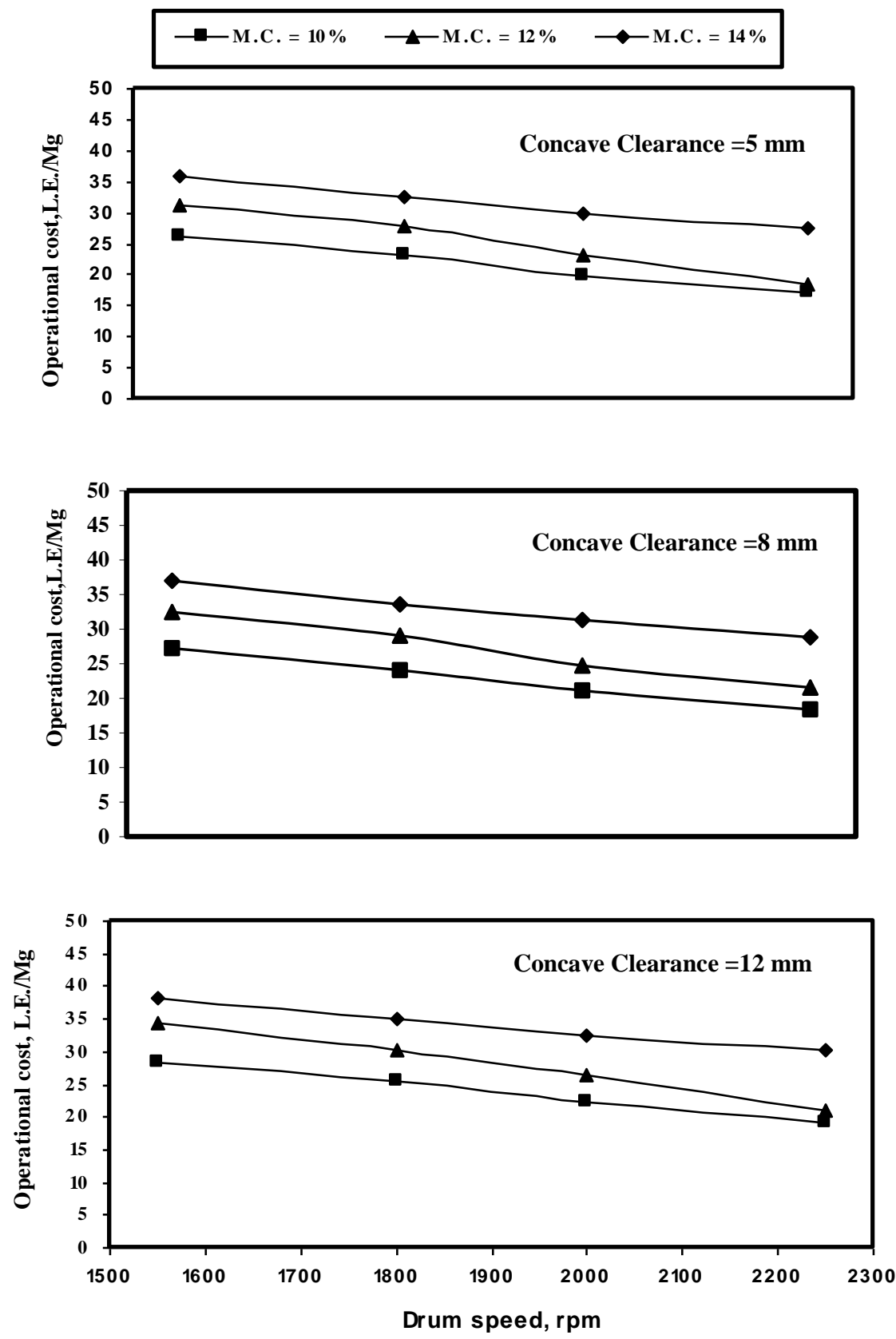

Fig.(11):Effect of drum speed on operational cost under different moisture contents and concave clearances at hammer thickness of $1.5 \mathrm{~mm}$. 

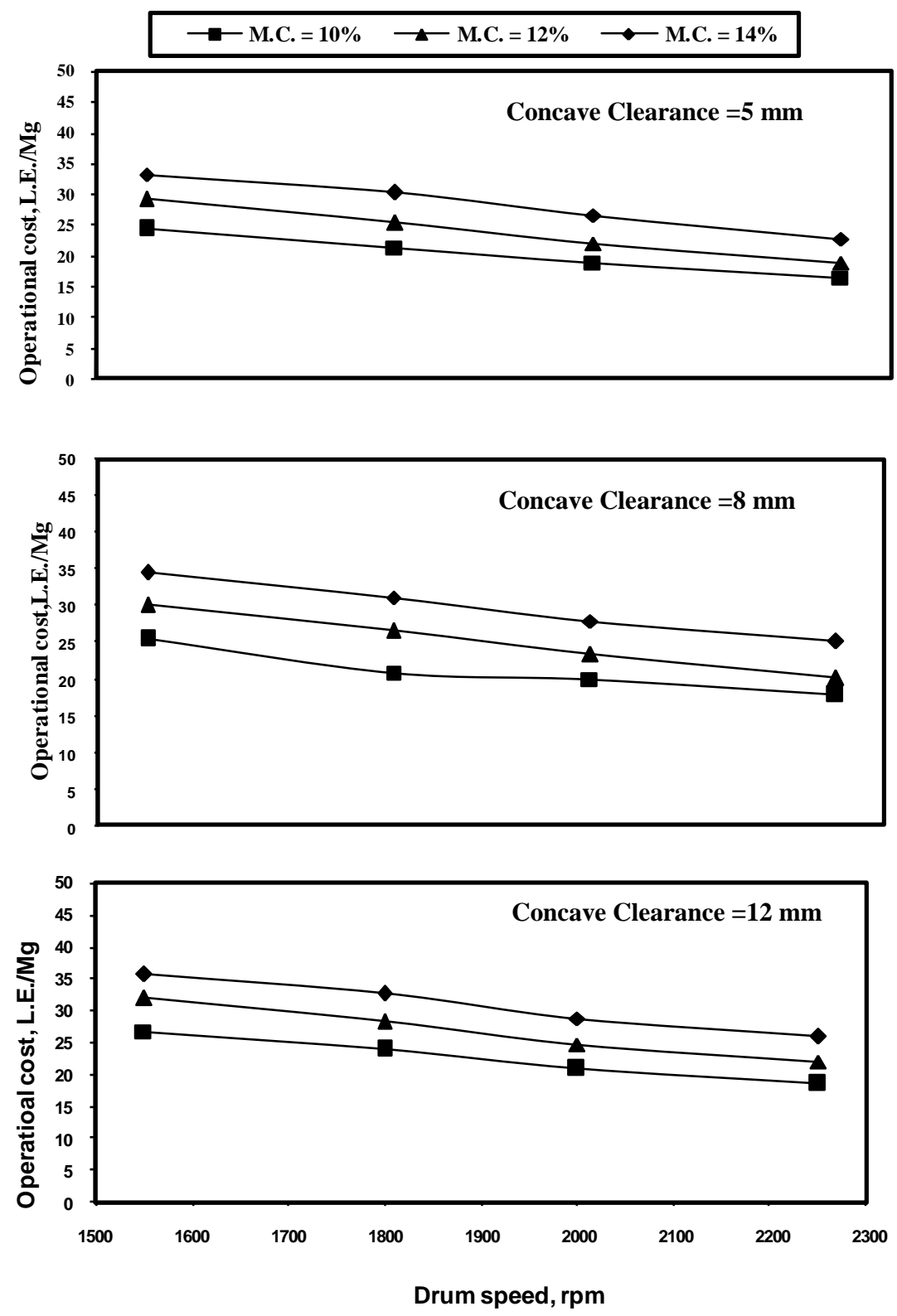

Fig.(12):Effect of drum speed on operational cost under different moisture contents and concave clearances at hammer thickness of $3 \mathrm{~mm}$. 

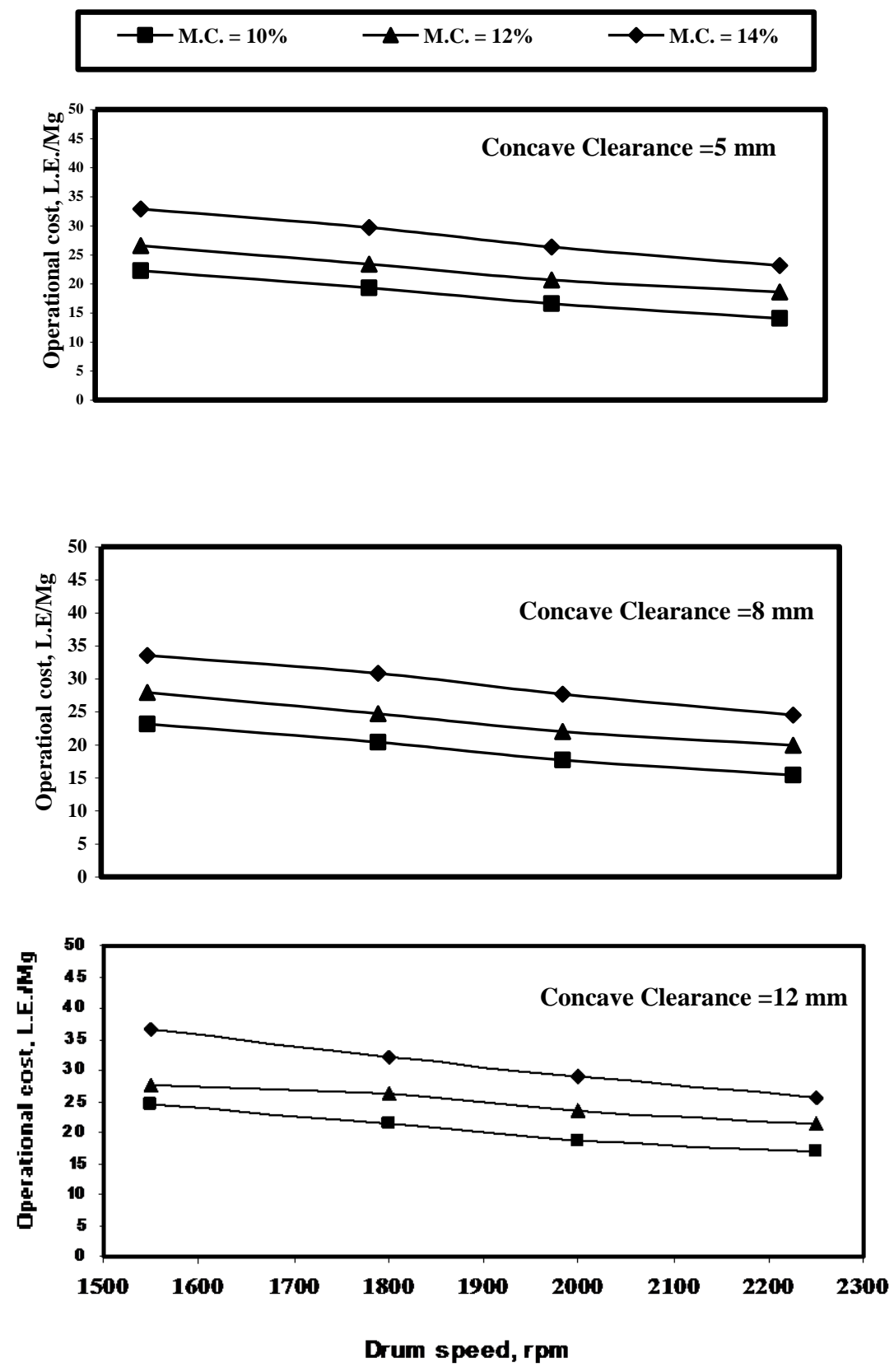

Fig.(13): Effect of drum speed on operational cost under different moisture contents and concave clearances at hammer thickness of $5 \mathrm{~mm}$. 


\section{CONCLUSION}

From this investigation, the obtained results can be concluded as follows: The proper conditions for operating the hammer mill used to produce pelleting feed were drum speed of $2250 \mathrm{rpm}(33.56 \mathrm{~m} / \mathrm{s})$, grain moisture content (10\%), concave clearance $(5 \mathrm{~mm})$ and hammer thickness $(5 \mathrm{~mm})$ by increasing percentage of fine milled corn and decreasing coarse milled corn while, to produce mash feed for commercial use can be achieved by using the mill at drum speed about $1550 \mathrm{rpm}(23.12 \mathrm{~m} / \mathrm{s})$,grain moisture content $(14 \%)$, concave clearance $(12 \mathrm{~mm})$ and hammer thickness $(1.5 \mathrm{~mm})$ by decreasing percentage of fine milled corn and increasing coarse milled corn and medium milled corn.

\section{REFERENCES}

Awady, M.N., I. Yehia, M.T. Ebaid and E.M. Arif. 2003. Development and theory of rice cleaner for reduced impurities and losses. Misr J. Ag. Eng., 20(4) : 53-68.

El- Gayar, S.M. and O.T. Bahnas, 2002. Garlic power production using a hammer mill. The $10^{\text {th }}$ annual conference of the Misr society of Ag. Eng., 16-17 Oct., 19 (4):293-306.

Ensminger M.E., J.E. Oldfield and W.W. Heinemann, 1990. Feeds \&Nutrition $2^{\text {nd }}$. Edition, The Ensminger publishing Company, California: 528-534 pp.

Hassan, M.A. 1994. Modifying and evaluation a small locally made mixmilling unit suitable for Egyptian poultry farms. Misr J. Ag. Eng., 11(2): 569 -584.

Hegazy, K.E.S., A.O. El-Ashhab, B.A. Hemeda and Mosa, M.A. Magda, 2002. Preparation and conversion of eggshell as hatchery by-product wastes to produce untraditional poultry feeds. Misr. J. Ag. Eng., 19 (2): 958-972.

Henderson, S.M., and P.L. Hansen, 1968. Hammer mill and Burr mill performance analyzed. Trans. of the ASAE., 11(3):399-402.

Ibrahim, M. K. 1982. Wet milling of wheat grain. M. Sc. Thesis, Faculty of Agric., Mansoura Univ.,Egypt. 
Martin, S. 1983. The effect of particle size on mixing and pelleting quality and production rates. Pages F1-F4 in: Proceedings of The First International Symp. on Particle Size Reduction in the feed Industry. Kansas State University, Manhattan, U.S.A.

الملخص العربي

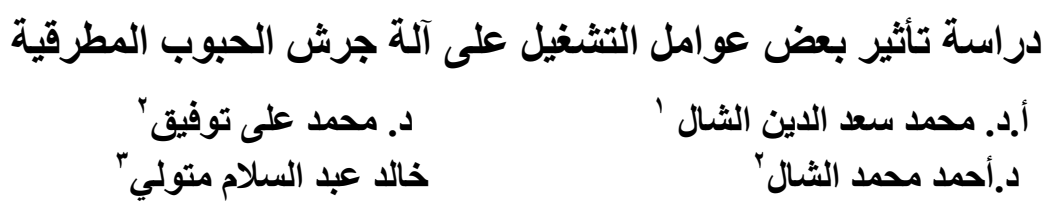

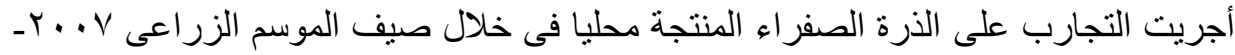

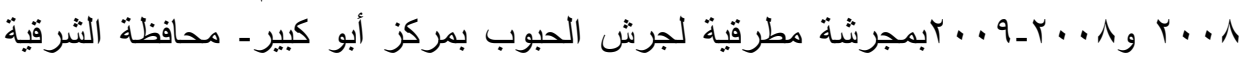

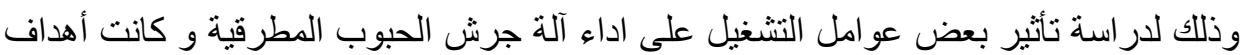

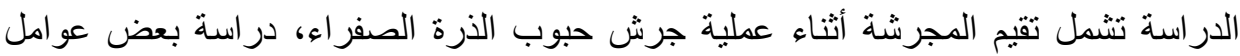

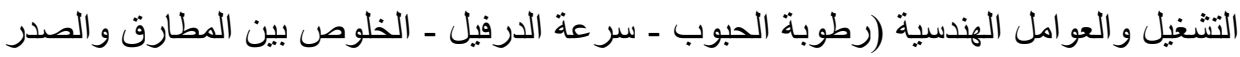

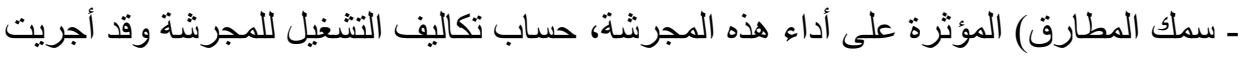

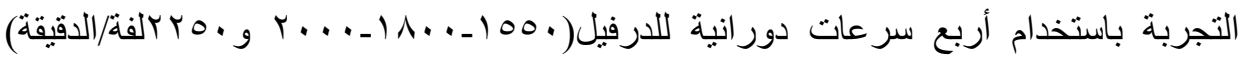

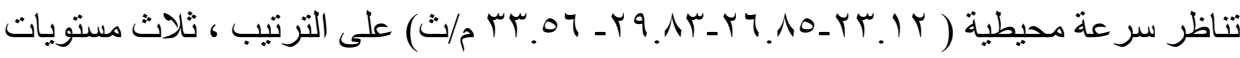

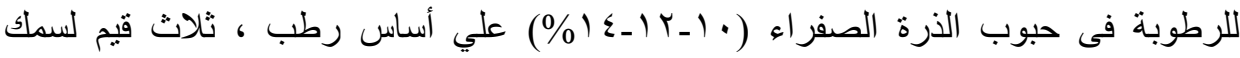

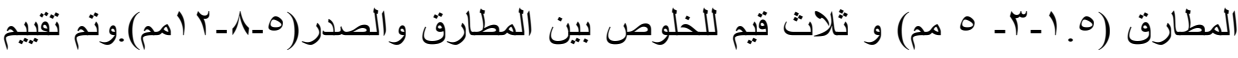

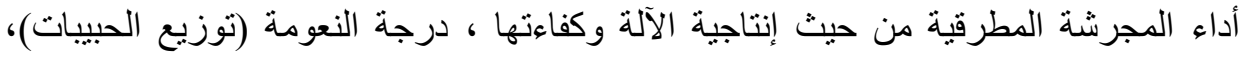

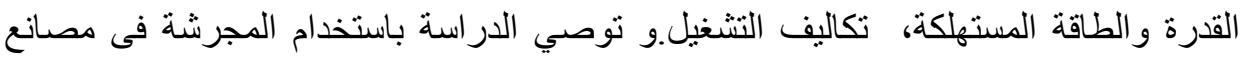

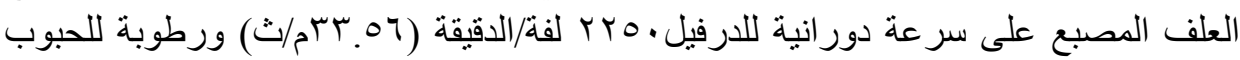

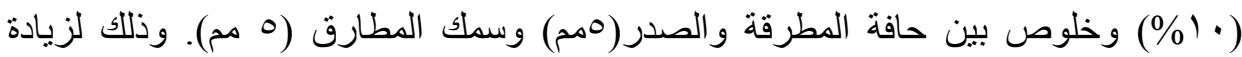

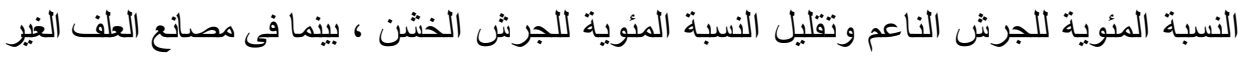

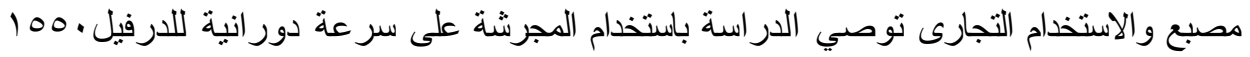

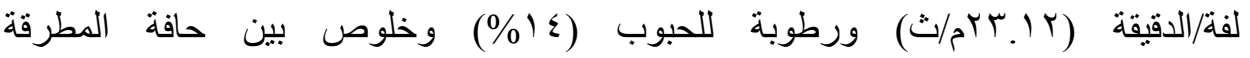

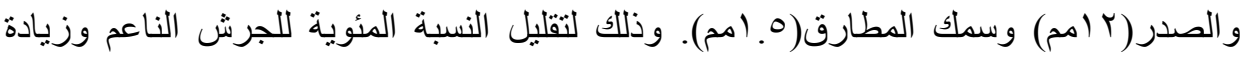
النسبة المئوية للجرش الوسط والخشن.

\footnotetext{
' أستاذ الهندسة الزر اعية المتفرغ - كلية الزر اعة - جامعة الزقازيق- مصر.

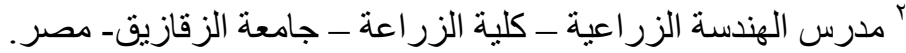

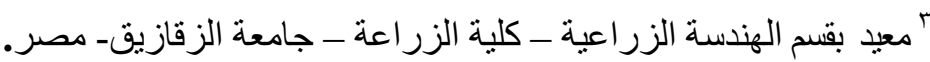

